\title{
A LEITURA LITERÁRIA NA SALA DE AULA: ESTRATÉGIAS DE LEITURA E O PROCESSO DE ALFABETIZAÇÃO
}

\author{
LITERARY READING IN THE CLASSROOM: READING \\ STRATEGIES AND THE LITERACY PROCESS
}

\author{
Joice Ribeiro Machado da SILVA ${ }^{1}$
}

\begin{abstract}
Resumo: Revisitar o ensino da leitura em turmas de alfabetização tem sido nosso tema de pesquisa recentemente. Nesse sentido, temos buscado romper com algumas práticas equivocadas para se ensinar a ler, como, por exemplo, as tradicionais questões de interpretação e a decodificação do texto. Para isso, nos pautamos numa perspectiva que considera o leitor como um sujeito ativo, que interage, num processo dialógico, com o texto e o contexto. Encontramos em nossos estudos duas referências importantes que nos auxiliam nessa jornada, a saber: as estratégias de leitura (HARVEY, GOUDVIS, 2007) e a descoberta de texto (BAJARD, 2012). O foco deste artigo é apresentar o trabalho desenvolvido com as estratégias de leitura em uma turma de $1^{\circ}$ ano do Ensino Fundamental no ano de 2018. Utilizando prioritariamente a literatura infantil, criamos, junto com as crianças da turma, um caderno de registro com as atividades que envolvem as estratégias de leitura, batizadas por elas de "Meu álbum literário", e fomos, ao longo do ano letivo, arquivando os gráficos organizadores utilizados em cada estratégia ensinada. Acreditamos que, para consolidar o processo de alfabetização, faz-se necessário incentivar a leitura de literatura infantil e criar oportunidades metodológicas para que as crianças aprendam a ler literatura. Desse modo, encontramos na proposta das estratégias de leitura uma possibilidade eficaz para explorar a literatura infantil em sala de aula. Os resultados apontam que a construção do álbum permitiu destaque aos gráficos organizadores e à participação das crianças durante a elaboração do material. Além disso, tornou-se um material de apoio para futuras análises de como os aprendizes estão lidando com a literatura e como algumas estratégias se consolidaram durante a sistematização do trabalho.
\end{abstract}

Palavras-chave: Leitura. Estratégia de Leitura. Literatura infantil. Alfabetização.

Abstract: Revisiting the teaching of reading in literacy classes has recently become our subject of research. In this sense, we have sought to break with some misleading practices to teach reading, such as the traditional questions of interpretation and decoding texts. For this, we are guided by a perspective that considers the reader as an active subject, which interacts with the text and the context in a dialogical process. We find in our studies two important references that help us in this journey, namely: reading strategies (HARVEY, GOUDVIS, 2007) and the discovery of text (BAJARD, 2012). The focus of this article is to present the work developed with reading strategies in a 1st grade class in the year 2018. Using children's literature as a priority, we created, along with the children in the class, a logbook with activities which involve reading strategies. Named for them as 'My Literary Album', we went throughout the school year, filing the graphics organizers used in each strategy taught. We believe that in order to consolidate the literacy process, it is necessary to encourage the reading of children's literature, and to create methodological opportunities for children to learn to read literature. In this way, we find in the proposal of reading strategies an effective possibility to explore children's literature in the classroom. Results show that the construction of the album made it possible to highlight the organizing charts and the participation of the children during the elaboration of the material. In addition, it has become a support material for future analyzes of how learners are dealing with literature and how some strategies have been consolidated during the systematization of the work.

\footnotetext{
${ }^{1}$ Doutora em Educação pela Universidade Estadual Paulista (UNESP) Júlio de Mesquita Filho. Docente da Escola de Educação Básica (ESEBA) da Universidade Federal de Uberlândia. E-mail: joice.rbr@gmail.com
} 
Keywords: Reading. Reading Strategy. Children's literature. Literacy.

\section{Considerações iniciais}

Pensar sobre a formação do leitor e encontrar formas efetivas de garanti-la é minha função enquanto professora alfabetizadora; portanto, revisitar o ensino da leitura na escola tem sido para mim um desafio. A busca por alternativas levou-me a pesquisar sobre a constituição do leitor na escola e, nesse processo, deparei-me com a proposta metodológica sobre o ensino das estratégias de leitura estadunidenses (HARVEY e GOUDVIS, 2007; SOUZA, 2010). Esse tema tem sido parte dos meus estudos e de minhas pesquisas desde 2010. A partir desse encontro com as estratégias aprofundei a temática e defendi minha tese de doutoramento em 2014, atualmente propondo o ensino da leitura para além do processo de decodificação com o uso prioritariamente de literatura infantil. Essa proposta rompe com as tradicionais formas de se ensinar a ler na escola, a saber: leitura oral, questões de interpretação após o texto, cópia, ditado, entre outras (CHIAPPINI, 1997).

"Meu álbum literário" deu-se pela necessidade de registrar as atividades desenvolvidas de leitura com o $1^{\circ}$ ano do Ensino Fundamental. Há algum tempo tenho oportunizado um trabalho diferenciado para o ensino da leitura no período de entrada da criança na escola de Ensino Fundamental, com crianças em processo de alfabetização. Como professora no Colégio de Aplicação, denominado ESEBA - Escola de Educação Básica, vinculado à Universidade Federal de Uberlândia, no ano de 2018 surgiu a ideia, junto à turma de $1^{\circ}$ ano, de criar esse álbum para que tudo o que realizássemos sobre estratégia tomasse forma, concretude.

Para além do material de registro, meu foco era o de ensinar para as crianças uma forma de processar a leitura de livros literários, pois acredito no potencial da literatura que nos humaniza (CANDIDO, 2012) e, além disso, o de romper com práticas equivocadas utilizadas na escola para se ensinar a ler. Nesse sentido, o álbum literário auxiliou-me a mostrar que é possível, é viável e vale muito investir nessa metodologia.

Como resultado do trabalho, vislumbrei a criação do álbum e a forma como as crianças passam a entender e a se relacionar com a leitura. Ao longo do ano letivo foi possível perceber em outros contextos a utilização de algumas estratégias que foram ensinadas, sem a necessidade de pedir que as crianças as realizassem. Isso demonstra que a metodologia foi por elas incorporada, pois as crianças se mostraram capazes de utilizá-la autonomamente. 
Dentro da minha concepção de leitura, que considera o leitor como aquele que interage e dialoga com o texto (SILVA, 2014), considero as estratégias de leitura uma metodologia viável, que contribui de maneira efetiva para a constituição do leitor literário. Essa proposta permite uma ressignificação do uso da literatura, a qual deixou de ter na minha prática um viés voltado apenas para despertar o gosto ou como pretexto para o desenvolvimento de projetos de ensino. Tratando-se do período de alfabetização, tais práticas são bem comuns no âmbito escolar. Concordamos com Dalvi (2013), que nos diz ser um equívoco acreditar que a função do professor é apenas o de desenvolver o gosto pela literatura. É preciso e possível ir além.

Ao iniciar o ano letivo de $2018 \mathrm{com}$ o $1^{\circ}$ ano do ensino fundamental e lançar o questionamento sobre o que desejariam aprender, foi possível conciliar as expectativas de aprendizagens das crianças com a necessidade do ensino da leitura prevista no currículo. Aprender a ler é um desejo presente nas falas infantis. Apresentei a proposta metodológica para as crianças como algo que as ajudaria a se apropriarem da leitura, de modo geral, e da leitura de literatura, de maneira específica.

No início do ano havia três crianças alfabetizadas, porém a leitura delas estava pautada na decodificação. Essas crianças estavam convictas de que já sabiam "ler". Somente quando comecei o trabalho com as estratégias e com outra proposta para desenvolver a leitura denominada 'descoberta de texto', criada e desenvolvida por Bajard (2012), foi que elas perceberam que ler vai muito além de extrair o som das sílabas. Ao longo do ano, elas passaram da decodificação para a leitura, enquanto as demais se alfabetizavam.

Minha expectativa era que as crianças percebessem que, para ler, não bastava decodificar. Junto a isso, contribuir para o processo de alfabetização das crianças e para a formação do leitor literário. Assim, dentro desse contexto, criamos o caderno de registro do trabalho de literatura na sala de aula, batizado pelas crianças de "Meu álbum literário", o qual será apresentado neste artigo.

\section{O uso das estratégias de compreensão para as leituras literárias}

As etapas do trabalho foram previamente planejadas de modo gradativo, pois a própria proposta metodológica prevê essa ampliação. Comecei com a estratégia de ativar o conhecimento prévio, que é uma estratégia guia (GIROTTO; SOUZA, 2010), pois para todas as demais ativamos nosso conhecimento prévio, e fui ampliando para as mais complexas. $\mathrm{Na}$ sequência entraram as conexões texto-texto (leio uma palavra do livro e me lembro de outro livro), a conexão texto-leitor (leio uma palavra e me lembro de algo da minha vida). Depois 
passei para a visualização, que é a capacidade de criar imagens mentais daquilo que estou lendo e em seguida apresentei a inferência, que é a capacidade de ler nas entrelinhas. Por fim, chegamos à estratégia de questões ao texto, que é a capacidade de criar perguntas para o texto na busca de respostas. Há ainda a conexão texto-mundo, a sumarização e a síntese, mas elas precisam de total domínio da leitura e da escrita, além de um conhecimento de mundo um pouco maior; portanto, fica difícil realizá-las numa turma de $1^{\circ}$ ano. No momento em que desenvolvemos nossa tese sobre o ensino das estratégias de leitura numa turma de $5^{\circ}$ ano do ensino fundamental, foi possível explorar todas as estratégias (SILVA, 2014).

Essa metodologia considera três momentos: moldar, prática guiada e prática individual. No momento de moldar, com um livro em mãos vou mostrando como a estratégia a ser ensinada 'funciona'; momento de dar os conceitos da estratégia eleita. Por exemplo, se vou mostrar a visualização, digo o conceito, leio o livro e vou falando minhas visualizações para mostrar durante a leitura como pôr em prática essa estratégia.

O segundo momento, de prática guiada, é utilizado para repetir a estratégia que estou enfocando, mas agora há a participação das crianças. Nesse momento é hora também de ajustar e retomar o conceito da estratégia quando necessário. Se desejo explorar a estratégia de visualização e a criança me diz uma conexão texto-leitor, costumo dizer: "Puxa que bacana, você fez uma conexão, isso é muito bom, mas agora tente pensar na sua visualização se você conseguir". A ideia não é limitar, ao contrário. Ver a criança realizar outra estratégia é positivo porque se nota que ela entendeu a estratégia ensinada anteriormente. Como leitores, realizamos as estratégias necessárias conforme a leitura nos exige para compreender o texto, mas como se trata de um momento específico de ensino há a necessidade de didatização para que as crianças compreendam uma a uma.

O terceiro momento, de prática individual, não introduzo no $1^{\circ}$ ano. Seria o momento em que, sozinhos ao ler um livro, anotamos as estratégias (ou as utilizamos mentalmente). Mas para isso seria preciso total autonomia na leitura e na escrita, o que ainda não é o caso. Nesse momento também, faz-se uma breve avaliação no sentido de ouvir os comentários das crianças a respeito do livro lido. Como faço uma adaptação para o $1^{\circ}$ ano, essa breve avaliação sobre a história ocorre após a prática guiada, dialogando com as crianças sobre suas impressões da estratégia em si e da história.

A escolha do livro é cuidadosa, pois ele deve potencializar a estratégia enfocada, ter alta qualidade literária e gradativamente ser mais complexo. Como a dinâmica se inicia com o diálogo entre criança/professor/texto, não tive dificuldade para introduzir o trabalho e ter a 
participação das crianças, até mesmo porque ouvir uma história é algo que eles gostam muito e para isso um bom livro faz toda a diferença.

Essa proposta permite que a diversidade de ideias esteja sempre presente, porque a literatura mobiliza áreas diferentes em cada um, conforme o que cada um é, sente e entende o mundo. Penso que essa possibilidade de diálogos deixa a atividade mais interessante, porque a criança pode participar sem medo e sua fala será acolhida. Não há certo ou errado, mas visões diferentes.

É um desafio durante a atividade em si a garantia de espaço para que todos participem sem deixá-la enfadonha, cansativa. Após as primeiras estratégias e a partir do momento em que passam a dominar a dinâmica de trabalho, a participação deles é intensa e sempre há crianças mais falantes que sentem a necessidade de se manifestarem o tempo todo, silenciando as tímidas. A expectativa é encontrar equilíbrio e por isso a necessidade de propor táticas: em cada página lida apenas três crianças falam; dar voz a quem ainda não se manifestou. Enfim, tentativas de garantir o efetivo envolvimento e aprendizado de todas as crianças.

As metas e os objetivos para o ensino da leitura foram então traçados de modo que a cada semana fosse possível explorar uma estratégia de leitura e, de maneira gradual, realizar cada uma delas: ativar o conhecimento prévio, conexões (texto-texto e texto-leitor), visualização, inferência e questões ao texto. Ao final do ano, foi possível realizar a leitura de 35 a 40 obras literárias. Para cada livro literário uma estratégia foi estruturada de modo a seguir a proposta didática e, com isso, estruturou-se o álbum literário.

Nesse caderno, registramos todas as ações que se referiram ao ensino da leitura: as estratégias de leitura, as sessões de mediação e a utilização da biblioteca escolar com o registro semanal dos livros retirados para a leitura em casa. Porém, nosso foco aqui é para o ensino das estratégias de leitura.

A cada estratégia vivenciada, eu ia junto com eles, e com o apoio da estagiária bolsista PROGRAD - Programa de Bolsa de Graduação, organizando o álbum que se tornou um material que permitiu visualizar o trabalho de leitura de literatura na sala de aula. $\mathrm{O}$ material auxiliou a concretizar o trabalho realizado com as estratégias de leitura, de modo que foi possível registrar, pelo menos em parte, as relações dialógicas entre texto-criança-professor que ocorreram. Tomando assim concretude, esse procedimento foi utilizado durante todo o ano letivo. A seguir, algumas fotos do álbum mostram como ele se estruturou (imagem 1). 
Imagem 1 - Fotos dos álbuns literários
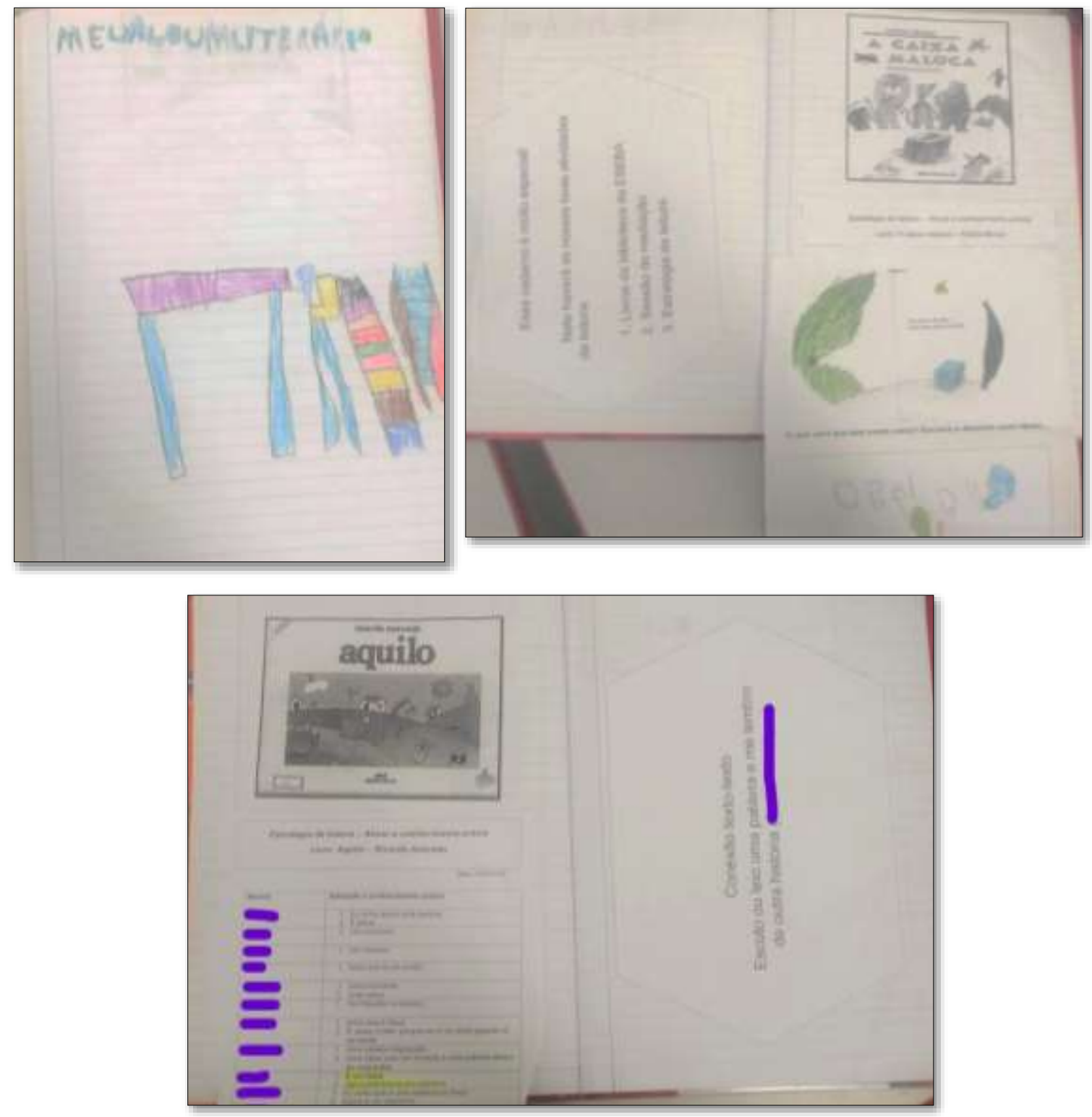

Fonte: Elaboração do próprio autor (2018).

Durante o desenvolvimento da atividade, a estagiária registrava as falas das crianças e as transcrevia para os gráficos organizadores, e esse material era colado pelas crianças no álbum. Feito isso, elas usavam a caneta marca-texto para que marcassem o seu nome.

Essa ação nos permitiu analisar durante o ano alguns comentários das crianças que se percebiam não realizando a estratégia: "Não tem meu nome aqui para marcar."; "Posso marcar de um amigo, porque não tem meu nome?" ou “Por que meu nome não aparece?”. Há diversas nuances possíveis de se interpretar essas falas. Desde o simples desejo de manusear a caneta 
marca-texto até o fato de incomodar-se por não ter conseguido realizar a estratégia ensinada. $\mathrm{O}$ desassossego era perceptível e analiso como produtivo o desejo de querer participar, mesmo que, para num primeiro momento, a solicitação fosse apenas para marcar o nome.

E nesse percurso, minha resposta enquanto professora era no sentido de mostrar que por ora não havia o nome dela, mas que, numa próxima atividade de leitura literária, seria possível participar ainda mais. Com o desenvolvimento e utilização do álbum, foi possível perceber que essas falas foram deixando de existir e a quantidade de participação nas atividades de estratégia aumentou gradativamente.

O caderno foi tomando forma à medida que foi capaz de eternizar o que as crianças pensaram, sentiram, imaginaram a cada estratégia ensinada. Os gráficos organizadores presentes na proposta metodológica ganham destaque, visto que há o registro de cada um deles. E, para além disso, permitiu que as próprias crianças os revisitassem semanalmente, tentando ler o que falaram, relembrando a história lida. Pelo menos uma vez por semana elas tinham contato com o álbum para organizarem as estratégias realizadas na semana anterior.

O próprio trabalho com a estratégia me auxiliou a realizar o diagnóstico inicial. Foi possível notar no registro do álbum literário a quantidade de participação das crianças durante a atividade e como isso mudou, ampliando-se conforme a proposta de ensino das estratégias avançava. A escola ainda não investe no trabalho com a compreensão do texto literário. Esse trabalho, por sua vez, tem sido usado ainda nessa escola e em tantas outras como pretexto para outras atividades, principalmente para se ensinar apenas a ler. Acredito que se trata de um equívoco teórico acerca de diversos pontos sobre o processo de alfabetização e a utilização da leitura na vida do sujeito. Cosson (2007) afirma que a leitura de literatura nos humaniza porque nos faz viver; porém, a leitura de literatura na escola vai de encontro a essa proposta.

As estratégias de leitura procuram explorar o texto por ele mesmo, buscando o diálogo com o autor e vivenciando a vida através dos temas que a literatura nos proporciona, tais como: medo, insegurança, morte, nascimento, alegria e tristeza, porque ler é vivenciar esses momentos. Sai de cena apenas a minha proposição sobre o livro e entram em cena as crianças que vão aos poucos aprendendo a dialogar com os textos, a saber falar sua opinião e a saber ouvir o outro. No atual contexto de ensino em que vivo, vejo que, tanto em curto como em longo prazo, haveria a necessidade de ampliar o trabalho de leitura que realizei com essa turma para que, ao ter continuidade, esse aprendizado não se perdesse em si mesmo.

O registro no álbum literário tem-se mostrado um material diferenciado que auxilia o rompimento da lógica de que a resposta do mediador é a única possível, é uma permissão para 
uma interface de diálogo cujo espaço para atitudes democráticas seja mais plausível (ZILBERMAN, 2009), processo no qual todos estão inclusos. A relação que as crianças aprendem a manter com a literatura é de possibilidades e não de respostas fechadas. O processo de "homogeneização da consciência", apontado por Silva (2008), deixa de existir nas relações estabelecidas na sala de aula, pois é valorizada a diversidade de respostas, de opiniões, de pensamentos. Essa heterogeneidade colabora, a meu ver, para que a compreensão seja conquistada mediante as leituras que se realizam com as crianças.

Além disso, outro aspecto relevante é o rompimento total com um dos principais materiais utilizados em sala, o livro didático, que, por sua vez, sugere uma única possibilidade de resposta aos docentes. Junto a isso, deixam de fazer sentido atividades presentes nos livros didáticos de texto/leitura/interpretação (em geral, para crianças não alfabetizadas, sendo essas atividades realizadas pelo professor). A interpretação de texto presente nos livros didáticos pode nos auxiliar a avaliar e pode ser, esporadicamente, utilizada pelo professor. O problema é acreditar que dessa forma estamos ensinando a criança a ler. Ao utilizar esse esquema tripé texto/leitura/interpretação, entramos num movimento de mais avaliar a leitura e perdemos muito tempo com isso, ou seja, muito avaliamos e pouco ensinamos. E, nesse ponto, ensinar as estratégias para crianças ainda em processo de domínio da leitura é instrumentalizá-las a se tornarem leitoras proficientes. É mostrar para elas, em atos reais de leitura, tudo o que eu, enquanto professora e modelo leitora, penso, sinto, imagino durante minha leitura e dizer para elas que podem e devem fazer dessa forma.

O álbum literário em si auxiliou no registro de todo esse processo vivido por mim e por eles durante as atividades. Demostra a diversidade de gráficos utilizados para as estratégias, pois são pensados conforme a atividade e o livro de literatura infantil. Ao longo do ano letivo, foram construídos em média 30 gráficos organizadores. Como exemplo dessa diversidade de gráficos, a seguir (Quadro 1) está o que foi utilizado para a estratégia de visualização do poema “Monstros", de Eugène Guillevic, retirado do livro de Jolibert (1994, p. 258).

\section{Monstros}

Existem monstros que são muito gentis, Que sentam contra você com os olhos fechados de ternura E sobre seu punho apoiam sua pata cheia de pelos

Uma noite -

Quando tudo for cor de púrpura no universo

Quando os rochedos retomarem suas trajetórias de loucos

Eles acordarão. 
Era o momento da prática guiada e, antes da minha leitura do poema, houve um tempo para que as crianças tentassem sozinhas ler o texto. Depois, quando realizei a leitura do poema, foi interessante notar o semblante de uma criança que arregalou os olhos numa expressão de pavor e medo, quando ouviu: "Eles acordarão". A visualização dela sobre a possibilidade do que iria acontecer demonstrou o quanto estava compenetrada no poema, externalizando fisicamente o que sentiu. Ao término, perguntei o que ela visualizou e a resposta foi: "Nossa, eles vão acabar com tudo!”.

Em seguida, conduzi a dinâmica de modo que fosse possível para elas perceberem a mudança de postura de um monstro aparentemente amigável no início do poema e que se transforma no final, quando algo muito estranho acontece. Houve ainda a curiosidade das novas palavras que surgiram e a necessidade de conceituá-las: púrpura e rochedos.

No final, houve o registro pela estagiária das visualizações das crianças, que organizamos em uma nuvem de pensamento usada em história em quadrinhos para sinalizar a ideia da imagem que representa o pensamento. Cada criança colou depois sua nuvem no álbum literário e o quadro 1 demonstra alguns exemplos de visualizações.

Quadro 1 - Gráfico organizador para a estratégia de visualização

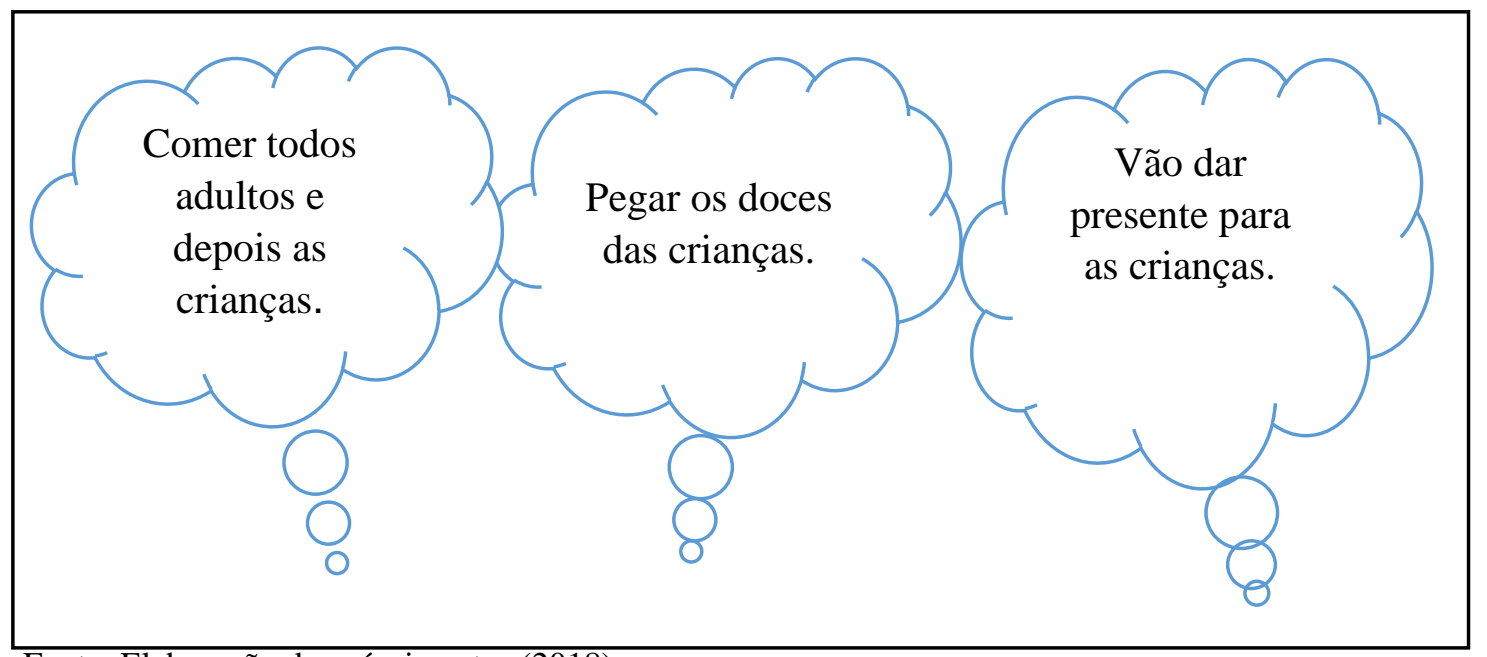

Fonte: Elaboração do próprio autor (2018).

Para cada estratégia houve um registro e assim o álbum se constituiu ao longo do ano letivo. Após ter explorado as estratégias planejadas, tinha como objetivo retomá-las para que as crianças não ficassem com dúvidas. Mas isso não aconteceu. Como o trabalho com as estratégias é cumulativo, mesmo focando, por exemplo, a estratégia de questões ao texto, as 
crianças faziam conexões, ativavam o conhecimento prévio, enfim, traziam para a leitura o que aprenderam.

Desse modo, comecei a incentivar a utilização das estratégias necessárias para a compreensão e passamos a registrar as que apareciam durante as leituras.

A cada estratégia ensinada, sempre retomava o conceito que a definia. As próprias crianças davam as respostas a esses questionamentos. Eram idas e vindas nesses conceitos e, mesmo sendo pequenas, elas conseguiam responder bem, considerando o nível exigido de complexidade que envolve o trabalho com o ensino da leitura.

- Conhecimento prévio: "Deixar vir à minha cabeça tudo o que sei e aprendi" $(\mathrm{PH} .)^{2}$;

- Conexão texto-leitor: "Quando leio uma palavra e lembro-me de alguma coisa que aconteceu comigo" (Ma.);

- Conexão texto-texto: "Leio uma palavra e lembro-me do nome de livro, desenho, filme" (MJ. e Mi.);

- Visualização: “É quando aparece uma imagem na minha cabeça. Quando me lembro de uma coisa na cabeça" (PH.);

- Inferência: "Tentar adivinhar o que vai acontecer na história" (JL.);

- Questões ao texto: "Perguntar o que vai acontecer" (JL).

Conforme as crianças foram se alfabetizando o trabalho foi ficando mais ágil e foi possível, no final do ano, auxiliá-las a realizarem o próprio registro, inclusive com os livros retirados por elas na biblioteca da escola. Esse fato foi decisivo para começar a explorar todas as estratégias possíveis durante as leituras.

Nesse sentido, irei apresentar um exemplo e discutir como todo o processo foi encaminhado e como se deu o registro no álbum. A história utilizada chama-se "Príncipe Cinderelo" de Babette Cole, e trata-se de uma versão bem divertida da história da Cinderela, porém, o personagem é um homem. Ele também tem três irmãos fortes e peludos e deseja muito ser como eles e sair à noite para a balada. Mas ao ser assessorado por uma fada atrapalhada, tudo sai às avessas.

\footnotetext{
${ }^{2}$ Utilizei as iniciais dos nomes das crianças, a fim de preservar a identidade delas.
} 
Imagem 2 - Capa do livro 'Príncipe Cinderelo'

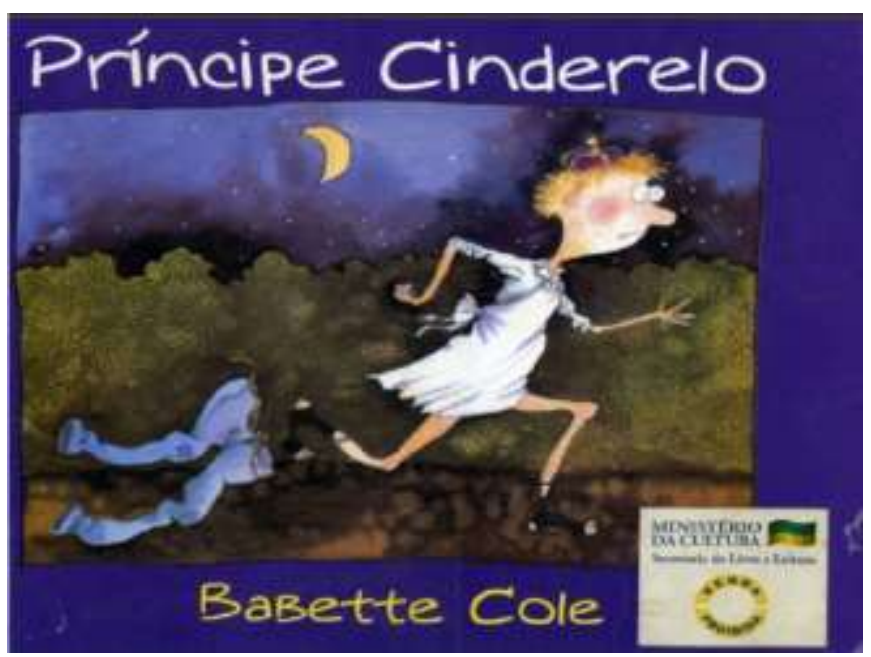

Fonte: Cole, 2006.

Essa história inicialmente leva-nos a realizar uma conexão texto-texto com o clássico infantil, mas, além dessa estratégia, outras vieram à tona: conexão texto-leitor, inferência e questões ao texto. Todas essas estratégias permitiram que houvesse uma melhor compreensão da história.

- Conexão texto-texto: durante a leitura, várias crianças realizaram algumas conexões. No quadro abaixo é possível notar.

Quadro 2 - Gráfico organizador utilizado para a estratégia de conexão texto-texto.

\begin{tabular}{|c|l|l|}
\hline Nome & Palavra, imagem ou trecho do texto & \multicolumn{1}{c|}{ Minha conexão } \\
\hline Ma. & Cinderelo & Igual à Cinderela. \\
\hline MJ. & Três irmãos & Lembrei da madrasta má da Cinderela. \\
\hline J. & Três & $\begin{array}{l}\text { Lembrei da história Três lobinhos e } \\
\text { um porco mal. }\end{array}$ \\
\hline JL. & Imagem da fadinha & A fadinha me lembrou do Peter Pan. \\
\hline JL. & Carrinho & Lembrei do filme Carros. \\
\hline
\end{tabular}

Fonte: Elaboração do próprio autor (2018).

- Conexão texto-leitor: como as crianças diferenciam ambas as estratégias, é possível observar que elas aparecem em momentos distintos e de modo bem tranquilo durante a atividade. 
Quadro 3 - Gráfico organizador utilizado para a estratégia de conexão texto-leitor

\begin{tabular}{|c|l|l|}
\hline Nome & Palavra, imagem ou trecho do texto & \multicolumn{1}{c|}{ Minha conexão } \\
\hline Mi. & $\begin{array}{l}\text { A imagem do príncipe limpando a } \\
\text { casa }\end{array}$ & $\begin{array}{l}\text { Me lembrou que eu limpo a casa da } \\
\text { minha avó. }\end{array}$ \\
\hline L. & Carrinho & $\begin{array}{l}\text { Lembrei dos meus carrinhos de } \\
\text { brinquedo. }\end{array}$ \\
\hline
\end{tabular}

Fonte: Elaboração do próprio autor (2018).

Girotto e Souza (2010, p. 67) afirmam que:

Quando começamos a instrução da estratégia com alunos, as histórias corriqueiras do dia a dia e as experiências são úteis para introduzir novas formas de pensar sobre a leitura. Os leitores fazem naturalmente conexões entre os livros e fatos de suas vidas. Quando escutam ou leem uma história, começam a conectar temas, personagens e problemas de um livro com o outro. No momento em que as crianças entendem o processo da conexão, não param mais de praticar essa estratégia, incorporando-a a sua vida. Isto as leva a pensar sobre situações maiores, mas expansivas, além do universo da escola, da casa e da vizinhança.

- Questões ao texto: essa estratégia auxilia a criança a interagir constantemente com o texto de modo a mantê-la interessada na busca pelas respostas àquilo que pergunta.

Elaborar perguntas ao texto significa estabelecer um diálogo intenso com a narrativa e com as ideias do autor. Portanto, essa capacidade, quanto mais aguçada, permite que tenhamos condições de fazer perguntas profundas ao texto e, com isso, a compreensão também é mais intensa (SILVA, 2014, p. 126).

Quadro 4 - Gráfico organizador utilizado para a estratégia de questões ao texto.

\begin{tabular}{|c|l|l|}
\hline Nome & Palavra, imagem ou trecho do texto & \multicolumn{1}{|c|}{ Minha interrogação ao texto } \\
\hline MJ. & $\begin{array}{l}\text { Ao observar a capa, MJ fica intrigada. } \\
\text { Ao fazer a conexão com a história da } \\
\text { Cinderela, pergunta: }\end{array}$ & $\begin{array}{l}\text { Será que é a princesa que chama o } \\
\text { príncipe para se casar? }\end{array}$ \\
\hline Al. & $\begin{array}{l}\text { Ao observar a cena em que o príncipe } \\
\text { Cinderelo corre da princesa e perde } \\
\text { suas calças, Al. pergunta: }\end{array}$ & $\begin{array}{l}\text { Será que agora ela vai procurar o } \\
\text { príncipe? }\end{array}$ \\
\hline As. & $\begin{array}{l}\text { Olhando a imagem dos três príncipes, } \\
\text { As. pergunta. }\end{array}$ & $\begin{array}{l}\text { Será que eles vão procurar } \\
\text { namorada? }\end{array}$ \\
\hline Al. & $\begin{array}{l}\text { Depois que Cinderelo se casa com a a } \\
\text { princesa, Al. questiona. }\end{array}$ & $\begin{array}{l}\text { Será que os irmãos vão ficar com } \\
\text { ciúmes? }\end{array}$ \\
\hline
\end{tabular}

Fonte: Elaboração do próprio autor (2018).

Quando termino a leitura, retomo as questões e, junto com as crianças, analisamos para ver quais puderam ser respondidas. A conexão com o clássico da Cinderela possibilitou boas perguntas que levaram as crianças a se envolverem com a história e compreenderem o que 
estava por trás de cada diálogo ou imagem do livro. Isso possibilitou a realização de algumas inferências, das quais destaco algumas.

Ao observar a capa e ler o nome Cinderelo, Is. infere que se trata de uma versão da original e diz: “ele perdeu as calças, eu vi as calças dele”. Ela não estava apenas descrevendo a imagem, mas inferindo que nessa história o personagem principal, assim como Cinderela, perde algo e, nesse caso, perde sua calça ao sair correndo. Do mesmo modo, $M$. realiza uma inferência ao ver a imagem da revista nas mãos de Cinderelo, cujo desenho mostra a figura de um cara forte, musculoso, ao contrário dele que é magricela. Ao observar a ilustração, ela diz: "Ele quer ser forte".

Tratando-se de uma cena no início da narrativa, ter a percepção para realizar essa inferência auxilia a criança a se preparar para o que virá pela frente e entender por que, no decorrer da história, a fada o transforma em forte e musculoso, mesmo que às avessas, visto que ele vira um grande macaco peludo. Girotto e Souza (2010, p. 76) afirmam que, "quando os leitores inferem e predizem, criam uma interlocução com o texto, usam seus conhecimentos prévios e o texto com a finalidade de estabelecer expectativas do que vai acontecer ou que informações o texto irá conter”.

Ao realizar essa inferência, $M$ auxilia também o processo de compreensão de toda a turma, pois há uma convocação para o diálogo proposto por ela aos demais. Se esse fato estava passando despercebido, deixa de sê-lo. Considerando que eles estão em processo de domínio da leitura e da escrita, realizar esse tipo de diálogo contribui para que percebam que ler é interagir com o texto, é analisar as imagens, é checar informações, é arriscar palpites. Essas ações mostram para as crianças que, para ler, precisamos fazer esse movimento de tentar compreender o que não está escrito no texto. Isso está muito além de extrair o som das letras.

Outra inferência ocorreu no final da história, quando a fada castiga os irmãos de Cinderelo. Uma das crianças se arrisca e diz: “Eles vão virar macacos!”. Seu desejo era que isso ocorresse de modo que os irmãos fossem punidos. Na verdade, eles o são, porém transformados em fadas da limpeza e não em macacos. Esse tipo de inferência mostra que a criança ficou conectada com a história até o fim e na tentativa de adivinhar um desfecho que lhe satisfizesse, sua inferência fica equivocada. Esse ocorrido auxilia a criança a perceber que nem sempre o que pensamos está correto e que isso também faz parte de uma postura leitora.

Por fim, o quadro abaixo, mostra como essa atividade com estratégia de leitura ficou registrada no material que denominamos em sala de aula de "Meu álbum literário". 
Quadro 5 - Registro de uma estratégia no álbum literário.

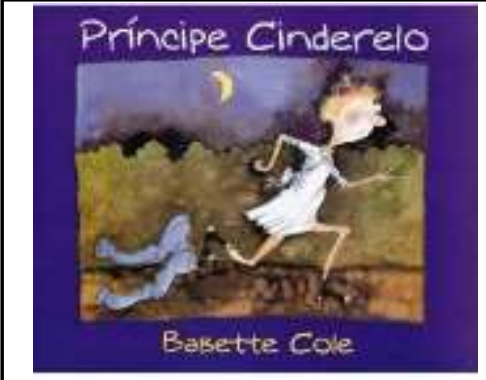

\section{Príncipe Cinderelo - Babette Cole}

Estratégias: conexão texto-texto, conexão textoleitor, questões ao texto e inferência.

$08 / 11 / 18$

Inferência:

Is.: Ele perdeu as calças, eu vi as calças dele.

Ma. :Ele quer ser forte.

Ma.: Eles vão virar macacos.

Conexão texto - leitor:

Mi.: A imagem do príncipe limpando a casa me lembrou que eu limpo a casa da minha avó. Lu.: Carrinho - Lembrei dos meus carrinhos de brinquedo.
Questões ao texto:

MJ: Será que é a princesa que chama o príncipe para se casar?

J.: Ele vai entrar?

Al.: Será que agora ela vai procurar o príncipe?

Al.: Será que os irmãos vão procurar namorados?

Al.: Será que os irmãos vão ficar com ciúmes?

Conexão texto - texto:

Ma.: Cinderelo - Igual à Cinderela

M J.: Três irmãos - Lembrei da madrasta má da Cinderela.

J.: Três - Lembrei da história Três lobinhos e um porco mal.

JL.: A fadinha me lembrou do Peter Pan.

JL.: Carrinho - Lembrei do filme Carros.

Fonte: Elaboração do próprio autor (2018).

\section{Considerações finais}

Fiquei muito satisfeita com o resultado do trabalho como um todo e com o formato que o álbum tomou. O que considerei muito significativo foi ver as crianças utilizando as estratégias em outras atividades, em outros espaços e momentos em que não solicitei que as realizassem. Um exemplo foi durante a troca de livros na biblioteca, que ocorreu no momento em que li a sinopse dos livros para ajudá-los na escolha. Eles começaram a realizar conexões ora com outros livros ora com a vida deles. A ideia é justamente esta: permitir que as estratégias sejam automatizadas, incorporadas para a vida na escola e fora dela. Por isso, penso que, se esse 
trabalho tivesse continuidade nos demais anos de ensino, essa autonomia seria consolidada. É preciso considerar que o trabalho com as estratégias precisa ser sistematizado e gradativo. Realizar atividades esporádicas não garante a incorporação das estratégias durante as leituras realizadas pelas crianças.

Dentro desse parâmetro, aplicar as estratégias de leitura e criar o álbum literário no qual os gráficos organizadores ficaram registrados e, com isso, o que as crianças pensam no exato momento em que ouvem a história, é contribuir para o aprendizado delas de que ler é um ato humano muito profundo e que não basta decodificar.

Trata-se da importância de ensinar para as crianças pequenas que ler é compreender. Conforme as crianças percebem que a compreensão é a chave para a busca de sentido e de significado, elas passam a se relacionar de maneira diferente com a leitura. Ficam mais atentas e questionam mais quando aparece alguma palavra ou expressão que não compreenderam. Essa ação é muito significativa, pois o desafio de formar leitores passa pela autorregulação da compreensão.

Além disso, o encontro com obras literárias auxilia a criar a necessidade do desejo de ler. Isso vai ao encontro também do meu desejo, ou seja, criar essa necessidade nas crianças. Ao realizar o encontro com as obras, analiso que esse processo no $1^{\circ}$ ano é bem mais tranquilo que no $5^{\circ}$, visto que as atividades relacionadas à leitura de literatura ao longo dos anos na escola, marcadas com cobranças de trabalhos e inúmeras atividades desenvolvidas depois, desanimam os estudantes. Obviamente que alguma atividade desse tipo pode ser feita, mas penso que ela deva ser subserviente à leitura e não o contrário, em que a leitura torna-se pretexto para a criança ter, por exemplo, que realizar uma produção textual. $\mathrm{O}$ trabalho com as estratégias foge a esse enfoque porque o foco é aprendê-las para compreender o texto.

Outro destaque é o envolvimento das crianças durante as atividades propostas e a possibilidade de posicionar-se mediante a leitura. Como citei anteriormente, trata-se de uma proposta que permite constantemente uma relação dialógica entre texto-criança, criança-criança e criança-professora. Há espaço para as diversas vozes que ecoam durante a leitura. Não haverá depois uma cobrança da minha parte para quem fez ou não a estratégia durante a leitura. Mas é interessante notar que há o desejo, por parte das crianças, de ter o registro do seu nome no álbum literário.

O álbum literário tornou-se uma possibilidade avaliativa que foge às tradicionais avaliações, inclusive as chamadas leituras orais. Nessa proposta de trabalho com as estratégias de compreensão, não há necessidade de realizar prova escrita, chamada oral ou qualquer outro 
mecanismo avaliativo. Os gráficos organizadores que são definidos como mapas do pensar sistematizam a atividade. Esses gráficos, inspirados na elaboração de Mclaughlin (2003), permitem uma melhor visualização do aprendizado da criança, pois o que ela pensou no momento em que ouviu a leitura ficou registrado. Nesse sentido, o álbum literário se tornou um precioso caderno de registros. Em anos anteriores os gráficos eram colados no caderno utilizado todos os dias e ficavam misturados às demais atividades realizadas. Tal dinâmica de organização do caderno impedia vislumbrar toda a sequência realizada com as estratégias. A necessidade de organizar tudo em um único lugar se deu para atender meu desejo de concretizar e mostrar esse trabalho para os meus pares, mas percebi que está para além disso. O álbum mostrou uma participação intensa das crianças, visível através dos gráficos organizadores e, ao final do ano letivo, puderam avaliar, juntamente comigo, a funcionalidade ou não do material. O retorno dado por elas, enfim, foi muito positivo.

\section{Referências}

BABETE, C. Príncipe Cinderelo. São Paulo: Martins Fontes, 2006.

BAJARD, È. A descoberta da língua escrita. São Paulo: Cortez, 2012.

CANDIDO, A. Textos de intervenção. Seleção e apresentação e notas de Vinícius Dantas. São Paulo: Duas Cidades. Ed. 34, 2002.

CHIAPPINI, L. (org.). Aprender e ensinar com textos didáticos e paradidáticos. São Paulo: Cortez, 1997.

COSSON, R. Letramento literário: teoria e prática. São Paulo: Contexto, 2007.

DALVI, M. A; REZENDE, N. L. de; JOVER-FALEIROS, R. (Orgs.). Leitura de literatura na escola. São Paulo: Parábola, 2013.

GIROTTO, C. G. G. S; SOUZA, R. J. Estratégia de leitura: para ensinar alunos a compreender o que leem. In: SOUZA, R. J. de. [et al]. Ler e compreender: estratégias de leitura. Campinas - SP: Mercado das Letras, 2010.

GUILLEVIC, E. Monstros. In: JOLIBERT, J. Formando crianças produtoras de texto. São Paulo: Artmed, 1994.

HARVEY, S.; GOUDVIS, A. Strategies that work. Teaching comprehension for understanding and engagement. USA: Stenhouse Publishers \& Pembroke Publishers, 2007.

MCLAUGHLIN, M. Guide comprehension in the primary grade. International Reading Association, 2003. 
SILVA, E. T. A produção da leitura na escola: pesquisas e propostas. São Paulo: Ática, 2008.

SILVA, J. R. M. O ensino das estratégias de compreensão leitora: uma proposta com livros de literatura infantil. 2014. 224 f. Tese (Doutorado em Educação) - Faculdade de Ciências e Tecnologia, Universidade Estadual Paulista, Presidente Prudente.

SOUZA, R. J. de. [et al]. Ler e compreender: estratégias de leitura. Campinas - SP: Mercado das Letras, 2010.

ZILBERMAN, R. A escola e a leitura de literatura. In: ZILBERMAN, R.; RÖSING, T. M. K. (Orgs.) Escola e leitura: velha crise, novas alternativas. São Paulo: Global, 2009.

Recebido em: 10/02/2019 Aceito para publicação em: 14/03/2019 